\title{
Effect of some heavy metals on the growth and development of Pleurotus tuber-
} regium

\author{
Akpaja EO ${ }^{a}$, Nwogu NA ${ }^{b^{*}}$ and Odibo EA ${ }^{a}$ \\ ${ }^{a}$ Department of Plant Biology and Biotechnology, University of Benin, P. M. B. 1154, Benin City, Edo State, Nigeria \\ ${ }^{b}$ Nigerian Institute for Oceanography and Marine Research, P. M. B. 4015, Sapele, Delta State, Nigeria
}

Akpaja EO, Nwogu NA, Odibo EA 2012 - Effect of some heavy metals on the growth and development of Pleurotus tuber-regium. Mycosphere 3(1), 57-60, Doi 10.5943/mycosphere/3/1/6

The effects of five heavy metals (cadmium, copper, mercury, lead and zinc) on the growth and fruit body production in Pleurotus tuber-regium was investigated. Lead sulphate, zinc sulphate, copper sulphate, cadmium nitrate and mercury chloride were added to garden soil at concentrations of 0 , $0.125,0.25,0.5,1.0$, and $2.0 \mathrm{mmol}$ per $3 \mathrm{~kg}$ of soil. Sclerotia of the test mushroom were used to inoculate the artificially contaminated soil. Mercury prevented growth and fruit body production in $P$. tuber-regium. Fungal morphometry was greatly affected by lead. The heavy metal content in the fungal biomass complex increased with increase of heavy metal concentration in the soil. The highest concentration $(183.06 \mathrm{mg} / \mathrm{kg}$ ) was found in zinc at $2 \mathrm{mmol} / \mathrm{L}$.

Key words - bioaccumulation - heavy metals - morphology - white-rot fungi

\section{Article Information}

Received 12 January 2012

Accepted 16 January 2012

Published online 19 February 2012

*Corresponding Author: Nwogu NA - e-mail - nwogunkem@yahoo.com

\section{Introduction}

Mushrooms are valuable health foods, low in calories, high in vegetable proteins, iron, zinc, chitin, fibre, vitamins and minerals. The consumption of edible mushrooms is increasing, even in the developed world. Mushrooms have been also reported as therapeutic foods, useful in preventing diseases such as hypertension, hypercholesterolemia, and cancer. These functional characteristics are mainly due to their chemical composition (Manzi et al. 2001). In recent years, considerable attention has been focused on the bioaccumulation of heavy metals in fruit bodies of some mushrooms (Zhu et al. 2011, Oghenekaro et al. 2008, Demirbas 2001). Compared to green plants, mushrooms can build up large concentrations of some heavy metals such as lead, cadmium and mercury. However, until now, there is only scattered information about the physiological and morphological effects of heavy metals on mushrooms.

Heavy metals present in the environment can directly interact with extracellular enzymes of fungi. However, to cause physiological and morphological response, heavy metals must be taken up by the fungus. Some heavy metals are important for fungal metabolism, where as others have no known biological role. The same metals are often toxic at concentrations only a few times greater than those required (Baldrian 2003)

Pleurotus tuber-regium (Fr.) Singer is a tuberous wild species of white-rot basidiomycetes that produces fruit bodies or sporophores from a globose sclerotium; it occurs in both tropical and sub-tropical regions of the world (Isikhuemhen \& LeBauer 2004). Oghenekaro et al. (2008) showed that P. tuber-regium was able to bioaccumulate some heavy metals. The objective of the present study was to determine the physiological and morphological effects of 
Table 1 Days to primordial emergence in Pleurotus tuber-regium

\begin{tabular}{lllllll}
\hline \multicolumn{7}{l}{ Concentration $(\mathbf{m m o l} / \mathbf{L})$} \\
Metals & $\mathbf{0}$ & $\mathbf{0 . 1 2 5}$ & $\mathbf{0 . 2 5}$ & $\mathbf{0 . 5}$ & $\mathbf{1 . 0}$ & $\mathbf{2 . 0}$ \\
\hline Cadmium & $13.33 \pm 1.76^{*}$ & $16.33 \pm 0.33$ & $12.00 \pm 0.58$ & $16.00 \pm 2.65$ & $17.33 \pm 0.30$ & $12.33 \pm 0.33$ \\
Copper & $13.33 \pm 1.76$ & $17.33 \pm 0.33$ & $11.00 \pm 2.08$ & $11.33 \pm 0.33$ & $12.00 \pm 1.73$ & $13.00 \pm 2.08$ \\
Mercury & $13.33 \pm 1.76$ & 0.00 & 0.00 & 0.00 & 0.00 & 0.00 \\
Lead & $13.33 \pm 1.76$ & $16.00 \pm 0.58$ & $17.00 \pm 0.58$ & $9.67 \pm 0.33$ & $20.33 \pm 0.67$ & $17.33 \pm 2.91$ \\
Zinc & $13.33 \pm 1.76$ & $16.00 \pm 0.58$ & $20.67 \pm 0.33$ & $14.33 \pm 0.33$ & $19.00 \pm 1.53$ & $10.33 \pm 2.03$ \\
\hline
\end{tabular}

*Mean of triplicate determination \pm S.E

five heavy metals on the vegetative growth of P. tuber-regium.

\section{Materials and Methods}

\section{Sclerotia collection}

Sclerotia of $P$. tuber-regium were obtained from Ekiuwa market, Benin City, Edo State, Nigeria.

\section{Heavy metals}

The salts of the heavy metals - lead sulphate $\left(\mathrm{PbSO}_{4}\right)$, zinc sulphate $\left(\mathrm{ZnSO}_{4} \cdot 7 \mathrm{H}_{2} \mathrm{O}\right)$, copper sulphate $\left(\mathrm{CuSO}_{4} .5 \mathrm{H}_{2} \mathrm{O}\right)$, cadmium nitrate $\left(\mathrm{Cd}\left(\mathrm{NO}_{3}\right)_{2} \cdot 4 \mathrm{H}_{2} \mathrm{O}\right)$ and mercury chloride $\left(\mathrm{HgCl}_{2}\right)$ came from the Department of Plant Biology and Biotechnology Laboratory, univer-sity of Benin.

\section{Soil collection and preparation}

Garden soil at the Faculty of Education, University of Benin, was collected using a hand trowel. The soil was sieved and $3 \mathrm{~kg}$ of soil was loaded into each of 78 perforated plastic bowls $(7 \times 16 \mathrm{~cm})$.

\section{Treatment of soil with heavy metals}

Each salt was prepared at $0,0.125$, $0.25,0.50,1.0$ and $2.0 \mathrm{mmol} / \mathrm{L}$ of sterile distilled water and $500 \mathrm{ml}$ of each solution was thoroughly mixed with the soil, and replicated three times. The control lacked any heavy metal.

\section{Inoculation of contaminated soil}

Seventy-eight sclerotia pieces, each weighing $20 \mathrm{~g}$ were soaked for 3 hours in water. The sclerotia were then soaked in dilute sodium hypochlorite solution for 15 minutes to remove contaminants. They were then sown 2 $\mathrm{cm}$ deep in the artificially contaminated soil contained in the plastic bowls. The bowls were incubated at ambient temperature $\left(26 \pm 2^{\circ} \mathrm{C}\right)$ and periodically watered to ensure that the environment was kept humid. The fruit bodies were harvested 7 days after primordial emergence and dried in an oven at $100^{\circ} \mathrm{C}$ for 48hours. The following parameters were determined: time of primordial emergence, stipe length, stipe diameter, cap diameter and heavy metal analysis of fruit bodies.

\section{Determination of heavy metals in fruit bodies of mushroom}

For elemental analysis, an atomic absorption spectrometer (Pye Unicam, Model 919) was used. Lead and cadmium in mushroom samples were determined using a GBC 3000 graphite furnace for atomic

Table 2 Heavy metal concentrations $(\mathrm{mg} / \mathrm{kg}$ ) in fruiting bodies of Pleurotus tuber-regium.

\begin{tabular}{lllllll}
\hline Metals & \multicolumn{2}{l}{ Concentration of heavy metals in soil (mmol/L) } & & & \\
\hline O & $0.430^{*}$ & 0.520 & 17.860 & 24.350 & 34.380 & 37.310 \\
Copper & 0.189 & 0.280 & 6.280 & 9.810 & 18.060 & 37.360 \\
Lead & 0.389 & 0.445 & 0.534 & 0.578 & 0.680 & 1.145 \\
Zinc & 52.304 & 73.223 & 83.686 & 104.608 & 130.760 & 183.064 \\
\hline
\end{tabular}

*Unit= mg/kg dry weight of mushroom. 
Table 3 Effect of heavy metals on stipe length $(\mathrm{cm})$, stipe diameter $(\mathrm{cm})$ and cap diameter $(\mathrm{cm})$ of Pleurotus tuber-regium

\begin{tabular}{lllllll}
\hline Metals & \multicolumn{5}{c}{ Concentration (mmol/L) } \\
& $\mathbf{0}$ & $\mathbf{0 . 1 2 5}$ & $\mathbf{0 . 2 5}$ & $\mathbf{0 . 5}$ & $\mathbf{1 . 0}$ & $\mathbf{2 . 0}$ \\
\hline \multicolumn{5}{c}{ Stipe length } \\
Cadmium & $7.70 \pm 0.66^{*}$ & $5.50 \pm 0.29$ & $5.80 \pm 0.23$ & $7.40 \pm 0.78$ & $7.60 \pm 0.38$ & $6.20 \pm 0.12$ \\
Copper & $7.70 \pm 0.66$ & $5.97 \pm 0.80$ & $5.97 \pm 0.80$ & $6.13 \pm 0.53$ & $6.03 \pm 0.91$ & $6.50 \pm 0.40$ \\
Mercury & $7.70 \pm 0.66$ & 0.00 & 0.00 & 0.00 & 0.00 & 0.00 \\
Lead & $7.70 \pm 0.66$ & $4.63 \pm 0.27$ & $5.73 \pm 0.58$ & $7.47 \pm 0.58$ & $4.83 \pm 0.38$ & $4.43 \pm 0.23$ \\
Zinc & $7.70 \pm 0.66$ & $6.20 \pm 0.32$ & $6.80 \pm 0.91$ & $5.23 \pm 0.23$ & $6.93 \pm 0.43$ & $7.50 \pm 0.35$ \\
& & & & & \\
& & & Stipe diameter & & & \\
Cadmium & $4.80 \pm 0.15^{*}$ & $4.70 \pm 0.25$ & $4.50 \pm 0.12$ & $4.50 \pm 0.20$ & $4.50 \pm 0.54$ & $4.50 \pm 0.23$ \\
Copper & $4.80 \pm 0.15$ & $4.13 \pm 0.19$ & $4.73 \pm 0.40$ & $4.60 \pm 0.27$ & $4.40 \pm 0.31$ & $4.40 \pm 0.31$ \\
Mercury & $4.80 \pm 0.15$ & 0.00 & 0.00 & 0.00 & 0.00 & 0.00 \\
Lead & $4.80 \pm 0.15$ & $4.60 \pm 0.27$ & $3.10 \pm 0.46$ & $5.10 \pm 0.12$ & $3.60 \pm 0.06$ & $3.30 \pm 0.12$ \\
Zinc & $4.80 \pm 0.15$ & $3.80 \pm 0.21$ & $4.17 \pm 0.24$ & $3.80 \pm 0.21$ & $4.60 \pm 0.27$ & $4.87 \pm 0.38$ \\
& & & & & \\
Cadmium & $7.97 \pm 0.90^{*}$ & $6.10 \pm 0.46$ & $9.87 \pm 0.41$ & $8.43 \pm 0.38$ & $6.27 \pm 0.66$ & $6.73 \pm 0.33$ \\
Copper & $7.97 \pm 0.90$ & $6.90 \pm 1.03$ & $10.27 \pm 0.12$ & $10.13 \pm 0.26$ & $9.83 \pm 0.99$ & $9.03 \pm 1.18$ \\
Mercury & $7.97 \pm 0.90$ & 0.00 & 0.00 & 0.00 & 0.00 & 0.00 \\
Lead & $7.97 \pm 0.90$ & $9.87 \pm 0.38$ & $3.33 \pm 0.52$ & $10.47 \pm 0.44$ & $3.77 \pm 0.47$ & $6.90 \pm 1.94$ \\
Zinc & $7.97 \pm 0.90$ & $6.57 \pm 0.27$ & $3.43 \pm 0.12$ & $7.17 \pm 0.54$ & $8.90 \pm 0.44$ & $9.90 \pm 0.38$ \\
\hline Meap diameter & & & &
\end{tabular}

$*$ Mean of triplicate determination \pm S.E.

absorption spectrometer. Other measurements were carried out in air/ acetylene flame.

\section{Statistical analysis}

Results are expressed as mean \pm S.E. of triplicate analysis. Data were evaluated using two-way analysis of variance (ANOVA).

\section{Results and Discussion}

The effect of the five heavy metals on primordial emergence is shown in Table 1. Mercury totally inhibited fruit body production in $P$. tuber-regium at all concentrations tested. The other heavy metals either delayed or slightly increased primordial emergence. Mercury is one of the most toxic metals for all white-rot fungi (Baldrian 2003). Baldrian \& Gabriel (1997) showed that mercury and cadmium exhibited the highest toxicity in the fungus Stereum hirsutum.

$P$. tuber-regium was able to bioaccumulate the heavy metals (Table 2) with the content of heavy metal in fruiting bodies reflecting the metal concentrations in their environment. The highest concentration (183.06 $\mathrm{mg} / \mathrm{kg})$ was found with zinc at $2 \mathrm{mmol} / \mathrm{L}$. The higher up take of zinc may be due to the essential role that it plays in fungal growth and metabolism. The toxicity of cadmium is well known, and this study shows the ability of $P$. tuber-regium to bioaccumulate this metal.

Apart from mercury which completely inhibited growth and fruit body production in $P$. tuber-regium, the other heavy metals affectted the morphometry of the mushroom (Table 3). Although P. tuber-regium was able to bioaccumulate the heavy metals, they affected both individual and complex metabolic process inducing morphological changes in the fungus as shown in difference between the stipe length stipe diameter and cap diameter of $P$. tuberregium grown in heavy metal fortified soil and that grown in the control. Lead produced the greatest effect on stipe length, stipe diameter, and cap diameter followed by cadmium (Table $3)$.

The interference of heavy metals with physiological, morphological, enzymatic and 
reproductive processes of white-rot fungi has ecological consequences. The effect on growth or morphology directly affects the enzymatic activities, which leads to changes of community structure and influences the energy flux in the ecosystem. Further studies to understand the molecular mechanisms of heavy metal accumulation by $P$. tuber-regium are needed in order to enhance its use in heavy metal bioremediation.

\section{References}

Baldrian P. 2003 - Interactions of heavy metals with white-rot fungi. Enzyme Microbiology and Technology 32, 78-91.

Baldrian P, Gabriel J. 1997 - Effect of heavy metals on the growth of selected woodrotting basidiomycetes. Folia Microbiology 42, 521-523.

Demirbas A. 2001 - Heavy metal bioaccumulation by mushroom from artificially fortified soils. Food Chemistry 74, $293-$ 301.
Isikhuemhen OS, LeBauer DS. 2004 - Growing Pleurotus tuberregium. In: Mushroom Growers Handbook 1. Mushroomworld-Heineart-Republic of Korea, 270-281.

Manzi P, Aguzzi A, Pizzoferrato L. 2001 Nutritional value of mushroom widely consumed in Italy. Food Chemistry 73, 321-325.

Oghenekaro AO, Okhuoya JA, Akpaja, EO. 2008 - Growth of Pleurotus tuberregium (Fr.) Singer on some heavy metalsupplemented substrates. African Journal of Microbiological Research 2, 268-271.

Zhu F, Qu L, Fan W, Qiao M, Hao H, Wang X. 2011 - Assessment of heavy metals in some wild edible mushrooms collected from Yunnan Province, China. Environmental Monitoring and Assessment 179, 191-199. 